\section{Bcl-2 constitutively suppresses p53-dependent apoptosis in colorectal cancer cells}

\author{
Ming Jiang and Jo Milner ${ }^{1}$ \\ Yorkshire Cancer Research P53 Laboratory, Department of \\ Biology, University of York, York YO10 5DD, UK
}

To dissect apoptotic genes governing the survival of colorectal carcinoma cells, we employed RNAi to silence Bcl-2 and Bcl- $x_{\mathrm{L}}$ in isogenic clones of p53+/+ and p53-/cells, and of $B a x+/-$ and $B a x-/-$ cells. We identify a novel proapoptotic function of $\mathrm{p} 53$ that does not require activation by genotoxic agents and that appears to be constitutively suppressed by Bcl-2. Silencing of $B c l-2$ induced massive p53-dependent apoptosis. The "Bcl-2/p53 axis" requires Bax and caspase 2 as essential apoptotic mediators. This newly discovered Bcl-2/p53 functional interface represents a key regulator of apoptosis which can be activated by targeting Bcl-2 in colorectal carcinoma cells.

Received October 21, 2002; revised version accepted February 6, 2003.

The pathways governing apoptosis in mammalian cells are complex, and the pro- and antiapoptotic permutations regulating cell viability vary according to species, cell type, and also between normal and cancer cells (for review, see Cory and Adams 2002; Johnstone et al. 2002; Reed 2002). Imbalance in favor of cell survival enables tumor progression and resistance to anticancer drugs. For example, the proapoptotic Bax gene is frequently mutated in DNA mismatch repair-deficient tumors, due to an unstable G8 tract at nucleotides 114-121 (Ionov et al. 1993; Rampino et al. 1997; Zhang et al. 2000). When both Bax alleles are mutated, the resultant Bax deficiency confers resistance to nonsteroidal anti-inflammatory drugs (NSAIDs) such as sulindac and indomethicin (He et al. 1999; Yamamoto et al. 1999; Zhang et al. 2000). Since predisposition to colorectal cancer is commonly associated with defective mismatch repair (Lynch 1999), mutation in Bax may explain acquired resistance to sulindac when administered as a chemopreventative agent. Indeed, sulindac enables clonal expansion of Bax-deficient cells in culture (Zhang et al. 2000) and may similarly favor clonal expansion of Bax-deficient cells in the colorectal epithelium of patients with inherited mismatch repair defects. However, Bax-deficient cells remain sensitive to 5-fluorouracil (5-FU), which activates p53-dependent apoptosis (Bunz et al. 1999; Zhang et al. 2000) and is the mainstream therapy for colorectal cancer.

[Keywords: p53; Bcl-2; Bcl- $\mathrm{x}_{\mathrm{L}}$; Bax; colorectal cancer; apoptosis] ${ }^{1}$ Corresponding author.

E-MAIL ajm24@york.ac.uk; FAX 01904-432808.

Article and publication are at http://www.genesdev.org/cgi/doi/10.1101/ $\operatorname{gad} .252603$.
Other pathways may also influence the survival of colorectal cancer cells. Here we have combined RNA interference (RNAi) with gene knockout to investigate the putative apoptotic roles of $\mathrm{p} 53, \mathrm{Bax}, \mathrm{Bcl}-2$, and Bcl- $\mathrm{x}_{\mathrm{L}}$ in cells cultured under normal growth conditions. Using isogenic clones of HCT116 human colorectal cancer cells, in which the parental cells contain normal p53 and Bax (Bunz et al. 1999; Zhang et al. 2000), our first experiments aimed to silence Bcl-2 expression by RNA interference. In mammalian cells, RNA interference is induced by short interfering RNA (siRNA) duplexes (Elbashir et al. 2001) which target homologous mRNA for degradation with exquisite selectivity and very high, sustained efficacy. Moreover, gene silencing by a single dose of siRNA is achieved within a few days (e.g., see Elbashir et al. 2001; Jiang and Milner 2002) and avoids the need for protracted long-term selection procedures such as those necessary to establish gene knockout cells. Thus RNA interference permits, for the first time, functional dissection of apoptotic pathways by silencing antiapoptotic genes in cells in which specific proapoptotic genes are already deleted.

We show that silencing of Bcl-2 induces massive p53dependent apoptosis, and that this occurs under normal cell growth conditions (i.e., without recourse to genotoxic drugs necessary to activate p53 as a transcription factor). Controls demonstrate that RNA interference per se is not sufficient to induce apoptosis in the parental HCT116 p53+/+ cells. The requirement for p53 is absolute, and other apoptotic genes such as Bax cannot substitute for $p 53$. Moreover the requirement for p53 was also evident in other human colorectal carcinoma cell lines, indicating that Bcl-2 silencing induces p53-dependent apoptosis in colorectal carcinoma cells in general. These observations place a novel proapoptotic function of p53 under Bcl-2 regulation, thus creating a constitutive Bcl-2/p53 axis regulating apoptosis in human colorectal epithelial cells. Further experiments using isogenic clones of $\mathrm{Bax}+/-$ and $\mathrm{Bax}-/-$ cells and caspase 2 siRNA clearly demonstrate that both Bax and caspase 2 are essential mediators of the Bcl-2/p53 apoptotic pathway.

\section{Results and Discussion}

\section{Selective silencing of Bcl-2 expression}

Initially we used paired isogenic clones of HCT116 p53+/+ and p53-/- cells (Bunz et al. 1999; Zhang et al. 2000), and to silence Bcl-2 expression we selected two Bcl-2 mRNA target sequences (Fig. 1A,B). Both are 100\% conserved between human and murine Bcl-2. Silencing of Bcl-2 expression was monitored by immunoblotting the Bcl-2 protein. It should be noted that a previous, well controlled study failed to clearly detect Bcl-2 in immunoblots of HCT116 cell lysates (Zhang et al. 2000), and we confirm this observation when using the same antibody (N19; Fig. 1D). However, other antibodies clearly detect Bcl-2 in the HCT116 cells and, importantly, show that Bcl-2 protein levels are equivalent in the $p 53+/+$ and p53-/- cells (Fig. 1E-H). The inevitable stress associated with the transfection process was not sufficient to activate p53 as a transcription factor in p53+/+ cells, as evi- 


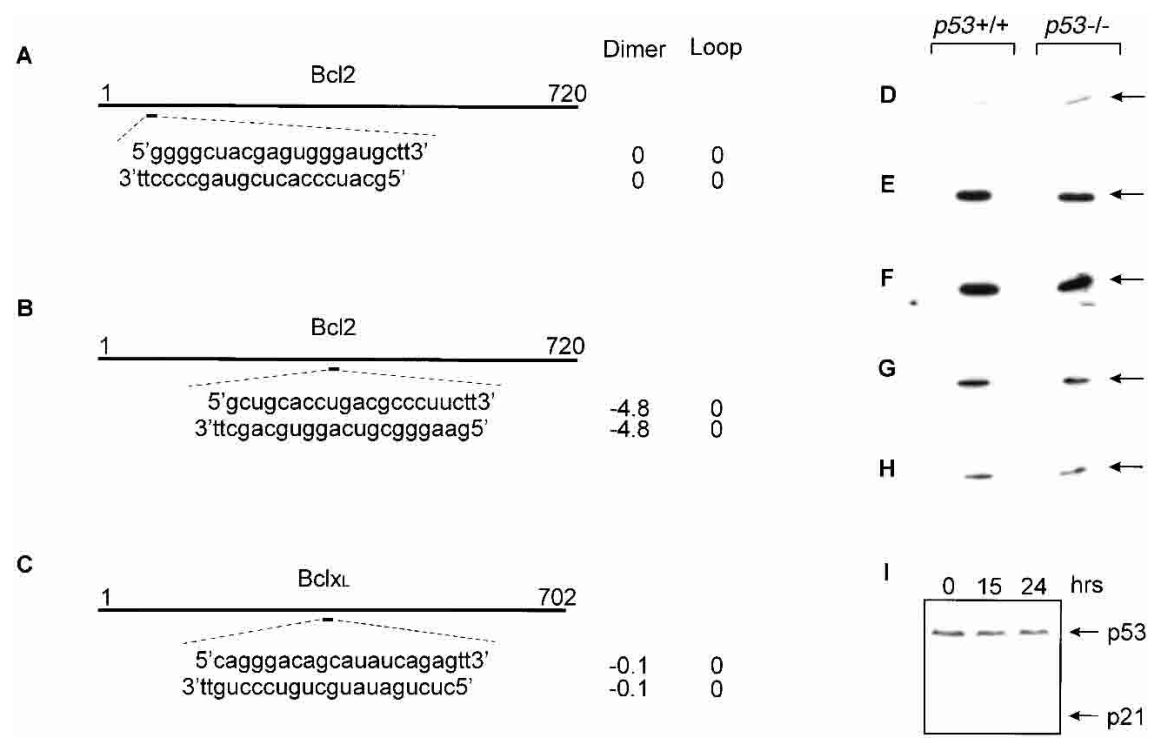

Figure 1. siRNA sequences used, and expression of Bcl-2 in HCT116 cells. $(A, B)$ Bcl-2 siRNA sequences, equivalent to Bcl-2 mRNA nucleotides 77-95 (A) and 354-372 (B). (C) Bcl- $\mathrm{x}_{\mathrm{L}}$ siRNA sequence, nucleotides 347-366. Predicted secondary structures with propensity for base-pairing out of register (dimers) or for forming stem-loop structures (loops) were derived using Vector NTI. Antisense RNA controls employed Bcl-2 antisense nucleotides 354-372, and Bcl- $\mathrm{x}_{\mathrm{L}}$ antisense nucleotides 347-366. Control siRNA (Jiang and Milner 2002) and lamin A/C siRNA (Elbashir et al. 2001) were also used in this study. ( $D-H)$ Immunoblots of Bcl-2 protein (arrows) in HCT116 p53+/+ and p53-/- cell lysates using different anti-Bcl-2 antibodies: N19 (D), C-2 $(E), \mathrm{Ab}-1(F$; this antibody gave nonspecific cross-reactivity with multiple cellular proteins; data not shown), $\mathrm{Ab}-2(G)$, and $\mathrm{BD}(H)$. The C-2 antibody was used in all subsequent experiments. $(I)$ Immunoblots of p53 and p21 in HCT116 p53+/+ cells at different times after transfection with control siRNA as indicated. duces massive apoptosis of HCT116 colorectal cancer cells and that this effect is dependent upon p53.

It was recently demonstrated that Bcl-2 can regulate an apoptotic pathway that is activated independently of mitochondrial cytochrome c release and Apaf-1/caspase 9 activation (Marsden et al. 2002). This raises the possibility that p53 may enable this cytochrome c-independent pathway, thus accounting for the observed differences in apoptosis between p53+/+ and p53-/- cells following silencing of Bcl-2 (Fig. 2). However, analysis of cytochrome c distribution clearly demonstrates release of cytochrome c into the cytosol in $p 53+/+$ cells undergoing apoptosis following treatment with Bcl-2 siRNA (Fig. 2E). In long exposures of the immunoblots, mitochondrial cytochrome c release was also evident in adherent p53+/+ cells treated with Bcl-2 siRNA, whereas no cytosolic cytochrome c was detectable in parallel cultures of p53-/- cells treated with Bcl-2 siRNA (data not shown). These results indicate that $B c 1-2$ silencing induces p53-dependent apoptosis via pathway(s) that involve the release of cytochrome $\mathrm{c}$ from the mitochondria. dent from the absence of up-regulation of p21, a p53 target protein (Fig. 1I). The Bcl-2 protein fell to barely detectable levels within $24 \mathrm{~h}$ of transfection with Bcl-2 siRNA (Fig. 2A). Interestingly, only one of the two Bcl-2 siRNAs silenced Bcl-2 expression [Bcl-2(b); Fig. 2], indicating that the mRNA sequence homologous to the noneffective siRNA (nucleotides 77-95; Fig. 1A) must somehow be protected from recognition and/or degradation by RNA interference. Such protection may arise due to localized mRNA secondary structure or protein-mRNA interactions (Jiang and Milner 2002). Control transfections included a random siRNA sequence (control siRNA; Jiang and Milner 2002) and lamin A/C siRNA, previously shown to suppress lamin A/C protein expression without inducing apoptosis (Elbashir et al. 2001).

\section{Bcl-2 silencing induces p53-dependent apoptosis}

By $48 \mathrm{~h}$, massive apoptosis was observed in the $p 53+/+$ cells transfected with Bcl-2 siRNA [Bcl-2(b); Fig. 2B-D]. Apoptosis in cells transfected with Bcl-2 antisense RNA (antisense sequence 354-372) was negligible (Fig. 2D) and equivalent to that observed for control siRNA. This confirms that apoptosis induced by Bcl-2 siRNA in p53+/+ cells is due to RNA interference. siRNA silencing of lamin A/C failed to induce apoptosis in either the p53+/+ or p53-/- cells (Fig. 2B). This demonstrates that the process of RNA interference per se is not sufficient to activate apoptosis in HCT116 p53+/+ cells. Unexpectedly, the p53-/- cells failed to undergo apoptosis following silencing of Bcl-2 expression (Fig. 2B-D). Thus we conclude that selective silencing of $\mathrm{Bcl}-2$ expression in-

\section{$B c 1-X_{L}$ silencing induces p53-independent apoptosis}

The integrity of p53-independent apoptotic pathways was next confirmed by silencing the $B c l-x_{L}$ gene, again using RNA interference. $B c l-x_{L}$ is an antiapoptotic gene (Boise et al. 1993), and in colorectal epithelial cells, a decrease in the ratio of $\mathrm{Bcl}-\mathrm{x}_{\mathrm{L}}: \mathrm{Bax}$ is sufficient to induce apoptosis (Zhang et al. 2000). Therefore we predicted that selective silencing of $B c l-X_{L}$ should induce apoptotic cell death in both $p 53+/+$ and $p 53-/-$ cells. Indeed, this proved to be the case. First we ascertained that the selected Bcl- $\mathrm{X}_{\mathrm{L}}$ siRNA sequence (Fig. 1C) effectively reduces Bcl- $\mathrm{x}_{\mathrm{L}}$ protein expression (Fig. 3A), and then we demonstrated its capacity to induce apoptosis (Fig. 3B,C). $\mathrm{Bcl}-\mathrm{x}_{\mathrm{L}}$ protein levels declined between 24 and $48 \mathrm{~h}$ posttransfection with Bcl- $x_{\mathrm{L}}$ siRNA, and subsequently apoptosis was observed in both the p53+/+ and p53-/- cells. This demonstrates that p53 is not required for $B c l-\mathrm{x}_{\mathrm{L}}-$ regulated apoptotic pathway(s) in colorectal epithelial cells. Further verification of p53-independent apoptotic pathways was obtained by treating the cells with sulindac, which is known to activate Bax-dependent apoptosis (Zhang et al. 2001). Sulindac induced apoptosis in both p53+/+ and p53-/- cells (Fig. 3D; see also Zhang et al. 2000). On the basis of these overall results, we conclude that the observed lack of apoptosis in p53-/- cells treated with Bcl-2 siRNA (Fig. 2) cannot be attributed to either loss of Bax or another apoptotic pathway suppressed by $\mathrm{Bcl}-\mathrm{x}_{\mathrm{L}}$. This is consistent with the isogenic nature of the two cell clones, and indicates that p53 is a selective requirement for apoptosis induced by $B c 1-2$ silencing. 
Jiang and Milner

A

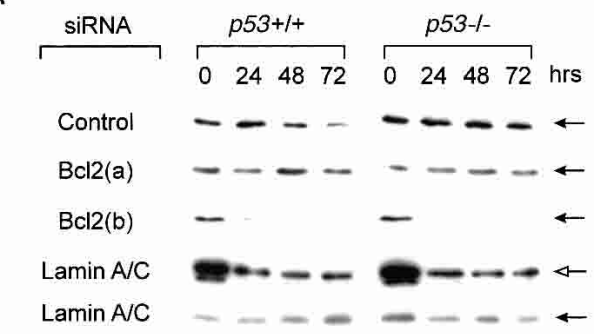

B

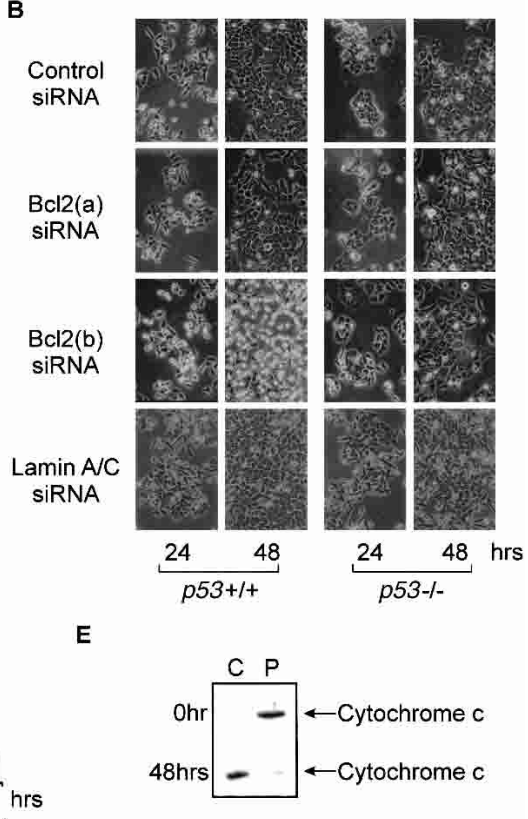

Figure 2. siRNA silencing of Bcl-2 induces p53-dependent apoptosis. Isogenic clones of p53+/+ and p53-/- HCT116 cells were cultured and transfected with siRNAs as described in the text. Transfection efficiency was $70 \%-80 \%$. (A) Immunoblots of Bcl-2 (closed arrows), and lamin A/C (open arrow). Times posttransfection with control siRNA, Bcl-2 siRNAs, and lamin A/C siRNA are as indicated. (B) Phase contrast images of $p 53+/+$ and $p 53-/-$ HCT116 cells at 24 and $48 \mathrm{~h}$ posttransfection with control siRNA, Bcl-2 siRNAs, or with lamin A/C siRNA. (C) Apoptotic cells confirmed by DNA laddering. M, marker; lane 1, control siRNA; lane 2, Bcl-2(a) siRNA; lane 3, Bcl-2(b) si-RNA. Cells were harvested for analysis $48 \mathrm{~h}$ posttransfection. (D) Annexin V-positive apoptotic cells detected by FACS analysis. Cells were harvested at 24 and $48 \mathrm{~h}$ posttransfection as indicated. White bars indicate control siRNA; bars with thick hatch marks indicate Bcl-2(a) siRNA; black bars indicate Bcl-2(b) siRNA; bars with thin hatch marks indicate Bcl-2(b) antisense RNA. In all subsequent experiments, Bcl-2(b) siRNA was employed to silence Bcl-2 expression, and apoptosis was confirmed by the independent techniques of DNA laddering and annexin V labeling with FACS analysis. (E) Cytochrome $\mathrm{c}$ distribution in cells at the time of transfection $(0 \mathrm{~h})$ and release into the cytosol of nonadherent cells collected 48 $\mathrm{h}$ following transfection with Bcl-2 siRNA in HCT116 p53+/+ cells. P, pellet fraction; C, cytosolic fraction.

Bax and caspase 2 are required for apoptosis following silencing of Bcl-2 or Bcl- $X_{L}$

Thus far our results indicate that Bcl-2 constitutively suppresses apoptosis in colorectal cancer cells grown in culture and that, following silencing of Bcl-2 expression, the process of apoptosis requires p53. This is novel and places a proapoptotic function of p53 under Bcl-2 regulation. Moreover, this proapoptotic function of p53 does not require treatment of cells with cytotoxic agents such as 5-FU. (Note that the process of RNA interference by itself is not sufficient to activate p53-induced apoptosis, as demonstrated by the lack of apoptosis in p53+/+ cells treated with lamin A/C siRNA; see above). In addition, we show that silencing of $B c l-X_{L}$ induces apoptosis in a p53-independent manner (Fig. 3). This is consistent with previous work identifying Bax as a major player in the apoptotic response of colorectal cancer cells (Ionov et al. 2000; Zhang et al. 2001; LeBlanc et al. 2002) and Bcl- $\mathrm{x}_{\mathrm{L}}$ as its antiapoptotic counterpart (when expressed exogenously; Zhang et al. 2001). These combined observations led us to reason that $\mathrm{Bcl}-2 / \mathrm{p} 53$ and $\mathrm{Bcl}-\mathrm{x}_{\mathrm{L}} / \mathrm{Bax}$ might represent functional partners governing apoptosis in human colorectal epithelial cells. Within this scenario, at least two putative apoptotic pathways might be envisaged: (1) Bcl-2/p53 may define an apoptotic pathway that is essentially independent of $\mathrm{Bcl}-\mathrm{x}_{\mathrm{L}} / \mathrm{Bax}$; or (2) $\mathrm{Bcl}-2 / \mathrm{p} 53$ and $\mathrm{Bcl}-\mathrm{x}_{\mathrm{L}} / \mathrm{Bax}$ may govern interrelated transitions in the apoptotic process. To discriminate be- tween these two alternatives we silenced, individually, $\mathrm{Bcl}-2$ and $\mathrm{Bcl}-\mathrm{x}_{\mathrm{L}}$ expression in isogenic clones of $\mathrm{Bax}+/-$ and $B a x-/-$ HCT116 cells (note that the apoptotic response of $\mathrm{Bax}+/-$ cells is equivalent to that of $\mathrm{Bax}+/+$ cells; Zhang et al. 2000). siRNA silencing of Bcl-2 and of $B c l-X_{L}$ induced massive apoptosis in $\mathrm{Bax}+/-$ cells but failed to induce significant apoptosis in $\mathrm{Bax}-/$ - cells (Fig. $4 C, D)$. This clearly demonstrates that Bax is required for apoptosis in both Bcl-2-regulated and $\mathrm{Bcl}-\mathrm{x}_{\mathrm{L}}$-regulated pathways.

The above results demonstrate that in colorectal carcinoma cells, the Bcl-2 and Bcl- $\mathrm{x}_{\mathrm{L}}$ cell death pathways share commonalities in their requirement for Bax, but differ in their requirements for $\mathrm{p} 53$. It is possible that $\mathrm{p} 53$ is required to prime a proapoptotic pathway that is selectively suppressed by Bcl-2, thus lowering the apoptotic threshold consequent to Bcl-2 silencing. To further dissect the functional links between Bcl-2, Bcl- $\mathrm{X}_{\mathrm{L}}$, p53, and Bax, we next investigated whether caspase 2 is also involved. Apoptosis induced by $B c l-2$ or by $B c l-x_{L}$ silencing was blocked when caspase 2 siRNA was cotransfected with either Bcl-2 siRNA or Bcl- $\mathrm{x}_{\mathrm{L}}$ siRNA, respectively (Fig. 4C; see Lassus et al. 2002 for caspase 2 siRNA sequence). siRNA silencing of caspase 2 alone (Fig. 4C), or transfection with antisense caspase 2 RNA (data not shown), had no apparent effect on cell viability. Overall these results demonstrate that both Bax and caspase 2 are required for apoptosis following silencing of either $B c 1-2$ or $B c l-X_{L}$ in $p 53+/+$ colorectal cancer cells. 
A

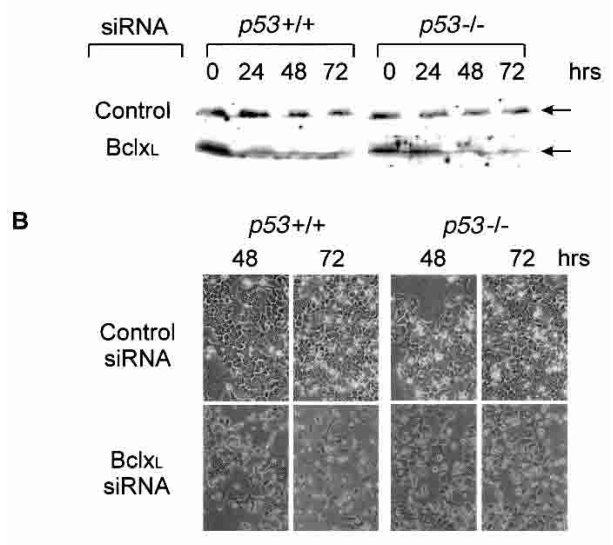

c

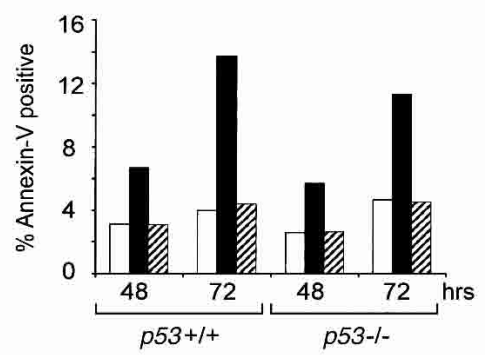

D

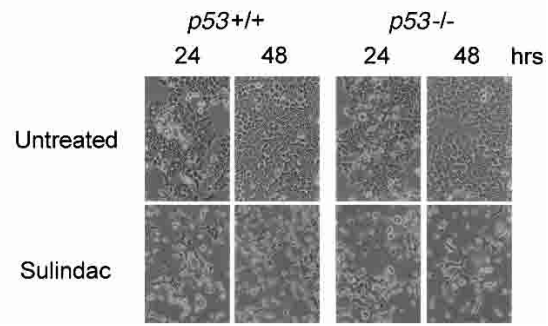

Figure 3. p53-independent apoptotic pathways in isogenic clones of HCT116 cells. $(A-C)$ siRNA silencing of the antiapoptotic gene Bcl- $\mathrm{x}_{\mathrm{L}}$ using the siRNA sequence shown in Figure 1C. (A) Immunoblot of Bcl- $\mathrm{x}_{\mathrm{L}}$ protein at different times after transfection with control siRNA or Bcl- $\mathrm{x}_{\mathrm{L}}$ siRNA. $(B)$ Phase contrast images of cells at 48 and $72 \mathrm{~h}$ posttransfection with control siRNA or Bcl- $\mathrm{x}_{\mathrm{I}}$ siRNA. $(C)$ Early apoptotic cells detected by annexin $\mathrm{V}$ labeling and FACS analysis. Cells were harvested for analysis at 48 and $72 \mathrm{~h}$ as indicated. White bars indicate control siRNA; black bars indicate $\mathrm{Bcl}-\mathrm{x}_{\mathrm{L}}$ siRNA; bars with thick hatch marks indicate $B c l-x_{L}$ antisense RNA. $(D)$ Apoptosis induced by treatment with sulindac. Phase contrast images of cells at 24 and $48 \mathrm{~h}$ posttreatment with sulindac, which activates Bax-dependent, p53-independent apoptosis (Zhang et al. 2000). Apoptosis was confirmed by DNA laddering and by FACS analysis of cells labeled with annexin $\mathrm{V}$ (not shown).

This is consistent with recent evidence that caspase 2 enables translocation of Bax into the mitochondria and subsequent mitochondrial membrane permeabilization marked by release of cytochrome c (Lassus et al. 2002).

\section{Effects of Bcl-2 siRNA on individual colorectal carcinoma cell lines of varying p53 status}

The above experiments involve isogenic clones of HCT116 cells and are thus tightly controlled for genetic variation. To test the generality of our observations, we silenced Bcl-2 in other human colorectal carcinoma cell lines, also defective for DNA mismatch repair and with defined p53 status (see Materials and Methods). In each case, the presence of wild-type p53 correlated with induction of apoptosis detectable $48 \mathrm{~h}$ posttransfection with Bcl-2 siRNA, whereas p53 deficiency correlated with background levels of apoptosis (Fig. 5). These results confirm our observations with isogenic clones of p53+/+ and p53-/- HCT116 cells and are consistent with the concept that Bcl-2 constitutively suppresses p53-dependent apoptosis in colorectal cancer cells.

\section{Conclusions}

Given the complexity and diversity of mammalian apoptotic pathways, it is perhaps not surprising that the application of novel methodologies such as RNA interference can disclose unexpected regulatory interactions. For example, it has been widely accepted that caspase activation requires mitochondrial disruption. However, experiments using RNA interference now indicate that, for caspase 2, the converse is the case and that mitochondrial disruption requires caspase 2 gene expression (Lassus et al. 2002). Another unexpected discovery challenges the long held belief that Bcl-2 inhibits apoptosis by safeguarding mitochondrial integrity, thereby preventing cytochrome c release and activation of caspase 9: it now appears that the Bcl-2 apoptotic pathway can function independently of caspase 9 and its activator Apaf-1 (Marsden et al. 2002).

In the present study we used isogenic cell clones and siRNA to obtain defined combinations of pro- and antiapoptotic gene expression in cells that are otherwise genetically equivalent. Our observations indicate a new cell death pathway in which Bcl-2 constitutively suppresses p53-dependent apoptosis. Apoptosis can also be induced by treating the cells with agents such as 5-FU to activate p53 (Zhang et al. 2000; data not shown). This is consistent with established evidence that activated p53 functions upstream of Bcl-2 in response to genotoxic stress (Strasser et al. 1994; for reviews see Cory and Adams 2002; Johnstone et al. 2002). To accommodate our present observations within the context of previous studies, we suggest that Bcl-2 constitutively suppresses a novel proapoptotic function of $\mathrm{p} 53$ and that exposure to genotoxic stress overrides Bcl-2 suppression by inducing the transactivation potential of $\mathrm{p} 53$. Once activated as a transcription factor, p53 has the capacity to alter the expression ratios of $\mathrm{Bcl}-2$ and $\mathrm{Bcl}-\mathrm{x}_{\mathrm{L}}$ (down-regulated) and Bax (up-regulated) in favor of apoptosis (Johnstone et al. 2002). From a clinical point of view this has proved very useful for anticancer therapy but carries the inherent risk of nonspecific cytotoxicity and genotoxicity caused by p53-activating agents. Our discovery that p53 possesses proapoptotic properties that appear to be constitutively active, albeit suppressed by Bcl-2, identifies Bcl-2 as a potential and promising target for anticancer therapy for colorectal cancer (see also Reed 2002), and demonstrates Bcl-2 accessibility for siRNA silencing. The survival of other epithelial tumors may be similarly susceptible to Bcl-2 silencing. With the development of RNA interference the selective silencing of specific genes is now a realistic possibility, and the continual inventive evolution of targeted delivery systems (e.g., see Hood et al. 2002) should enable application of RNA interference to prevent and to treat cancer.

This work also carries important implications for patients with inherited DNA mismatch repair deficiencies 


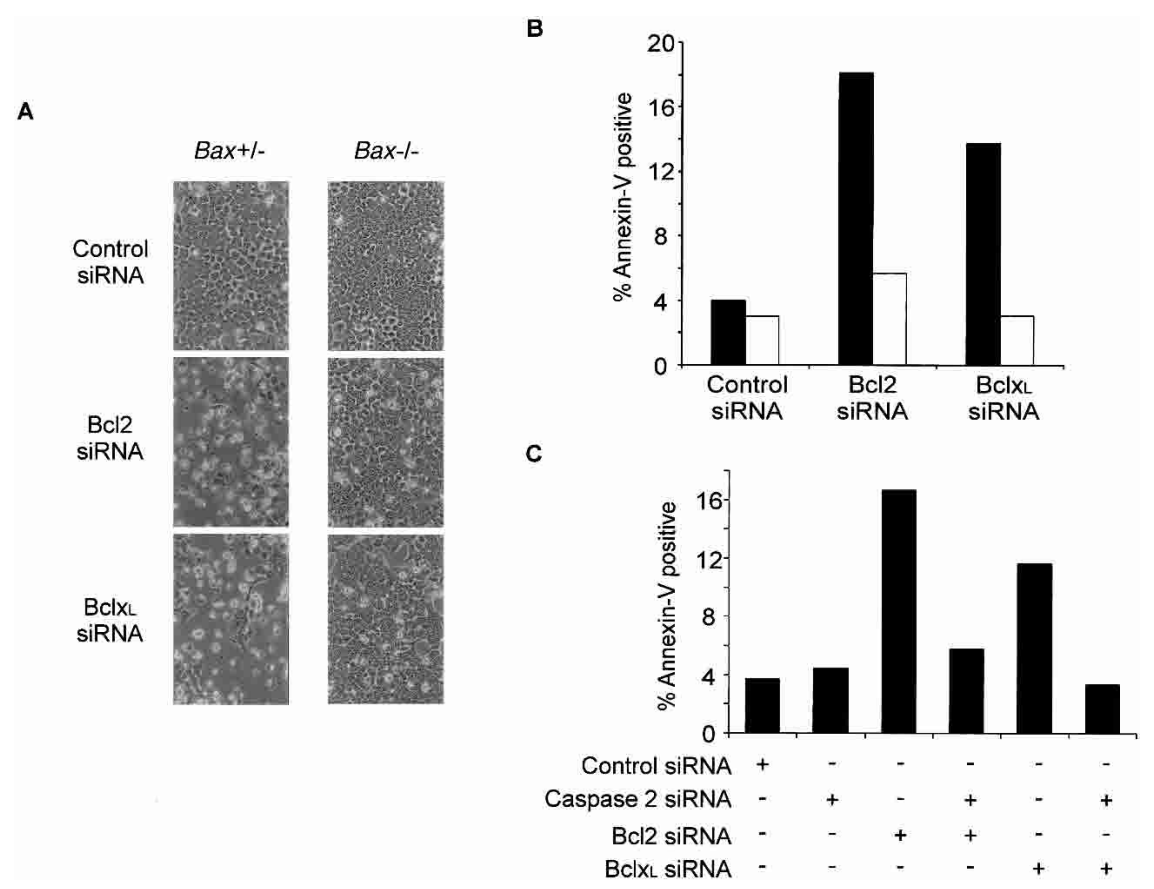

Figure 4. Apoptosis following silencing of Bcl-2 or Bcl- $\mathrm{x}_{\mathrm{L}}$ depends upon Bax and caspase 2. $(A)$ Phase contrast images of isogenic clones of $\mathrm{Bax}+/-$ and $\mathrm{Bax}-/-$ HCT116 cells at $72 \mathrm{~h}$ posttransfection with control siRNA, with Bcl-2 siRNA or with Bcl- $x_{\mathrm{L}}$ siRNA, as indicated. $(B)$ Apoptotic cells in isogenic clones of HCT116 cells detected by labeling with annexin V and FACS analysis. The cells were harvested at $72 \mathrm{~h}$ posttransfection with control siRNA, Bcl-2 siRNA, or Bcl- $\mathrm{x}_{\mathrm{L}}$ siRNA as indicated. Black bars indicate Bax+/- cells; white bars indicate Bax-/- cells. (C) Apoptotic cells in HCT116 p53+/+ cells (the same clone as used in Figs. 2, 3) $72 \mathrm{~h}$ following transfection with caspase 2 siRNA in combination with either Bcl-2 siRNA or Bcl- $x_{L}$ siRNA as indicated.

and associated predisposition to colorectal cancer. In particular, it argues against the use of sulindac as a chemopreventative in such patients, because it is well established that defective mismatch repair renders the Bax gene susceptible to mutation and favors clonal expansion of Bax-deficient cells (see the introductory text above). In the present study we demonstrate that Bax is an essential mediator of apoptosis regulated by the newly discovered Bcl-2/p53 pathway (see above). It follows that, in patients with mismatch repair defects, any selective pressure for Bax-deficient cells may exacerbate tumorigenesis and should be avoided.

Future studies will investigate whether the newly identified constitutive proapoptotic function of p53 is linked with apical apoptosis in the normal colorectal epithelium. If so, failure of apoptosis in colorectal epithelial tumors might reflect inappropriate suppression of intrinsic p53-induced apoptosis. A strong candidate in this regard is Bcl-2, which constitutively blocks p53-induced apoptosis and enables the survival of colorectal cancer cells (the present study). Such a model is consistent with the late onset of p53 mutation in the malignant progression of colorectal cancer. It also reenforces Bcl-2 as a prime target for the development of novel anticancer agents.

\section{Materials and Methods}

Cell lines and transfections

HCT116 clones were cultured in DMEM with 10\% FCS. All the cell clones were cultured with penicillin 100 units $\mathrm{mL}^{-1}$ and streptomycin $100 \mu \mathrm{g} \mathrm{mL}-1$ at $37^{\circ} \mathrm{C}$ in $5 \% \mathrm{CO}_{2}$ in air. Other human colorectal cancer cells lines, also defective for DNA mismatch repair (Branch et al. 1995), were: LoVo and RKO (p53 wild type); DLD1, LS174T, SW48, and HT29 (all p53 mutant). Note that although LS174T cells are genotypically wild-type for p53, they are phenotypically p53-deficient. For transfection, the cells were trypsinized and subcultured into 6-well plates $\left(10 \mathrm{~cm}^{2}\right)$ without antibiotics, $1.5 \times 10^{5}$ cells per well. Selected 21 nucleotide RNAs were synthesized and HPLCpurified (MWG) and annealed into siRNA duplexes according to the instructions supplied. Twenty-four hours after subculture, the cells were transfected with siRNA formulated into liposomes (Oligofectamine, Life Technologies) according to the manufacturer's instructions. The protocol includes a short incubation in serum-free medium, but controls demonstrated that this was not sufficient to activate a p53 response (see Results). The siRNA concentration was $0.58 \mu \mathrm{g}$ per $1.5 \times 10^{5}$ cells per well. The final volume of culture medium was $1.5 \mathrm{~mL}$ per well. Cells were harvested for analysis at various times thereafter, as indicated in Results and Discussion. Each experiment with HCT116 cells was carried out four or more times. Transfection efficiencies were established by transfecting with liposomes containing FITC-dextran (Jiang and Milner 2002). Antisense RNA controls were included in each experiment, using the respective antisense sequences for $\mathrm{Bcl}-2(\mathrm{~b}), \mathrm{Bcl}-\mathrm{x}_{\mathrm{L}}$, and caspase 2 (see Fig. 1A and text).

\section{Immunoblotting and mitochondrial \\ cytochrome c release}

For immunoblotting, the transfected cells were trypsinized and then washed in PBS, and an aliquot was removed for cell counting. The remaining cells were lysed in $50 \mu \mathrm{L}$ lysis buffer ( $150 \mathrm{mM} \mathrm{NaCl}, 0.5 \% \mathrm{NP} 40,50 \mathrm{mM}$ Tris at $\mathrm{pH} 8.0$ ) on ice for $30 \mathrm{~min}$. Samples were diluted 1:1 in $4 \times$ strength Laemlli's buffer. Proteins were resolved by $15 \%$ SDS-PAGE and electroblotted onto nitrocellulose membrane for antibody detection. Molecular weight markers and purified recombinant human p53 were included as markers (data not shown). The following antibodies were employed: for Bcl-2 = N19 and C-2 (Santa Cruz Biotechnology); $\mathrm{Ab}-1$ and $\mathrm{Ab}-2$ (Oncogene; note that $\mathrm{Ab}-1$ gave nonspecific background with multiple cellular proteins; data not shown); and $\mathrm{BD}$ (Fig. 1B; Pharmingen). The C-2 antibody gave the cleanest results and was subsequently used throughout this work. Lamin $\mathrm{A} / \mathrm{C}=$ antibody 636

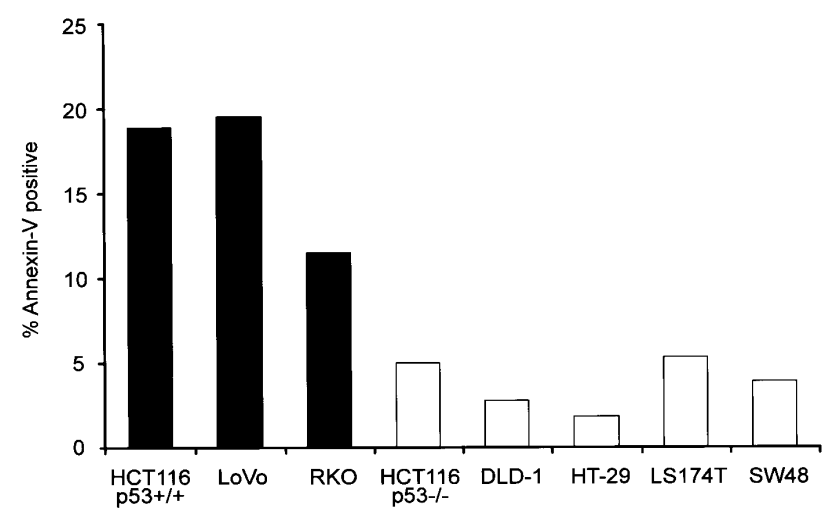

Figure 5. Apoptosis correlates with p53 status in individual human colorectal carcinoma cell lines following silencing of Bcl-2 expression. Cells were transfected with Bcl-2 siRNA, and apoptotic cells were determined after $48 \mathrm{~h}$ (as described in Fig. 2 legend and Materials and Methods). Black bars indicate cell lines expressing endogenous wild-type p53, white bars indicate p53-deficient cell lines. 
(Santa Cruz Biotechnology); Bcl- $\mathrm{x}_{\mathrm{L}}=\mathrm{Bcl}-\mathrm{X}$ antibody (Pharmingen; this antibody gave a relatively high nonspecific background); p53 = DO- 1 antibody (Oncogene); and caspase 2 = caspase-2L antibody (F-7; Santa Cruz Biotechnology). Visualization of bound antibodies was by enhanced chemiluminescence (Roche). Cell fractionations and cytochrome c determinations were carried out as described (Marsden et al. 2002, and its supplementary information).

Cell growth, cell cycle analysis, and apoptosis

Cell growth curves were determined by cell counting. Induction of apoptosis by sulindac (Fig. 3) employed sulindac sulphide $120 \mu \mathrm{M}$ (Calbiochem). For cell cycle analysis the cells were harvested, washed with PBS, and fixed in $90 \%$ ethanol overnight at $-20^{\circ} \mathrm{C}$. The fixed cells were pelleted, washed in PBS, and resuspended in PBS containing $0.1 \mu \mathrm{g} / \mathrm{mL}$ propidium iodide with $200 \mathrm{U} / \mathrm{mL}$ RNase A, and then analyzed by FACS. Apoptotic cells were identified using annexin-V-Fluos (Boehringer) following the manufacturer's protocol. Apoptosis was also verified by DNA laddering using the Suicide-track DNA ladder isolation kit (Oncogene) according to the manufacturer's instructions.

\section{Acknowledgments}

We thank Bert Vogelstein for generously making available the isogenic HCT116 clones of $p 53+/+, p 53-/-, B a x+/-$, and Bax-/- cells. This work was funded by a programme grant from Yorkshire Cancer Research to J.M.

The publication costs of this article were defrayed in part by payment of page charges. This article must therefore be hereby marked "advertisement" in accordance with 18 USC section 1734 solely to indicate this fact.

\section{References}

Boise, L.H., Gonzalez-Garcia, M., Postema, C.E., Ding, L., Lindsten, T., Turka, L.A., Mao, X., Nunez, G., and Thompson, C.B. 1993. Bcl-x, a bcl-2-related gene that functions as a dominant regulator of apoptotic cell death. Cell 74: 597-608.

Branch, P., Hampson, R., and Karran, P. 1995. DNA mismatch binding defects, DNA damage tolerance, and mutator phenotype in human colorectal carcinoma cell lines. Cancer Res. 55: 2304-2309.

Bunz, F., Hwang, P.M., Torrance, C., Waldman, T., Zhang, Y., Dillehay, L., Williams, J., Lengauer, C., Kinzler, K.W., and Vogelstein, B. 1999. Disruption of p53 in human cancer cells alters the responses to chemotherapeutic agents. J. Clin. Invest. 104: 263-269.

Cory, S. and Adams, J.M. 2002. The Bcl2 family: Regulators of the cell life-or-death switch. Nat. Rev. Cancer 2: 647-656.

Elbashir, S.M., Harborth, J., Lendeckel, W., Yalcin, A., Weber, K., and Tuschl, T. 2001. Duplexes of 21-nucleotide RNAs mediate RNA interference in cultured mammalian cells. Nature 441: 494-498.

He, T.C., Chan, T.A., Vogelstein, B., and Kinzler, K.W. 1999. PPAR $\delta$ is an APC-regulated target of nonsteroidal anti-inflammatory drugs. Cell 99: $335-345$.

Hood, J.D., Bednarski, M., Frausto, R., Guccione, S., Reisfeld, R.A., Xiang, R., and Cheresh, D.A. 2000. Tumor regression by targeted gene delivery to the neovasculature. Science 296: 2404-2407.

Ionov, Y., Peinado, M.A., Malkhosyan, S., Shibita, D., and Perucho, M. 1993. Ubiquitous somatic mutations in simple repeated sequences reveal a new mechanism for colon carcinogenesis. Nature 363: 558 561.

Ionov, Y., Yamamoto, H., Krajewski, S., Reed, J.C., and Perucho, M. 2000. Mutational inactivation of the proapoptotic gene Bax confers selective advantage during tumour clonal evolution. Proc. Natl. Acad. Sci. 97: 10872-10877.

Jiang, M. and Milner, J. 2002. Selective silencing of viral gene expression in HPV-positive human cervical carcinoma cells treated with siRNA, a primer of RNA interference. Oncogene 21: 6041-6048.

Johnstone, R.W., Ruefli, A.A., and Lowe, S.W. 2002. Apoptosis: A link between cancer genetics and chemotherapy. Cell 108: 153-164.

Lassus, P., Optiz-Araya, X., and Lazebnik, Y. 2002. Requirement for caspase 2 in stress-induced apoptosis before mitochondrial permeabilization. Science 297: 1352-1354.

LeBlanc, H., Lawrence, D., Varfolomeev, E., Totpal, K., Morlan, J.,
Schow, P., Fong, S., Schwall, R., Sinicropi, D., and Ashkenazi, A. 2002. Tumor-cell resistance to death receptor-induced apoptosis through mutational inactivation of the proapoptotic Bcl-2 homologue Bax. Nat. Med. 8: 274-281.

Lynch, H.T. 1999. Hereditary nonpolyposis colorectal cancer (HNPCRC). Cytogenet. Cell Genet. 86: 130-135.

Marsden, V.S., O'Connor, L., O'Reilly, L.A., Silke, J., Metcalf, D., Ekert, P.G., Huang, D.C., Cecconi, F., Kuida, K., Tomaselli, K.J., et al. 2002 Apoptosis initiated by Bcl-2-regulated caspase activation independently of the cytochrome c/Apaf-1/caspase 9 apoptosome. Nature 419: 634-637.

Rampino, N., Yamamoto, H., Ionov, Y., Li, Y., Sawai, H., Reed, J.C., and Perucho, M. 1997. Somatic frameshift mutations in the BAX gene in colon cancers of the microsatellite mutator phenotype. Science 275: 967-969.

Reed, J.C. 2002. Apoptosis-based therapies. Nat. Rev. Drug Discov. 1: $111-121$.

Strasser, A., Harris, A.W., Jacks, T., and Cory, S. 1994. DNA damage can induce apoptosis in proliferating lymphoid cells via p53-independent mechanisms inhibitable by BCL-2. Cell 79: 329-339.

Yamamoto, Y., Yin, M.J., Lin, K.M., and Gaynor, R.B. 1999. Sulindac inhibits activation of the NF-кB pathway. I. Biol. Chem. 274:2730727314.

Zhang, L., Yu, J., Park, B.H., Knizler, K.W., and Vogelstein, B. 2000. Role of BAX in the apoptotic response to anticancer agents. Science 290: 989-992. 


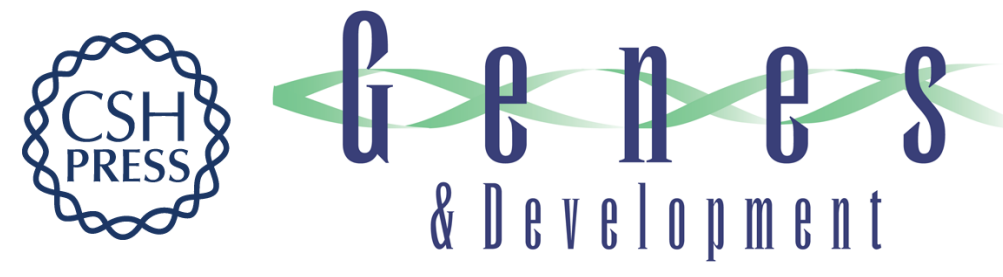

\section{Bcl-2 constitutively suppresses p53-dependent apoptosis in colorectal cancer cells}

Ming Jiang and Jo Milner

Genes Dev. 2003, 17:

Access the most recent version at doi:10.1101/gad.252603

References This article cites 19 articles, 6 of which can be accessed free at: http://genesdev.cshlp.org/content/17/7/832.full.htmI\#ref-list-1

License

Email Alerting Receive free email alerts when new articles cite this article - sign up in the box at the top Service right corner of the article or click here.

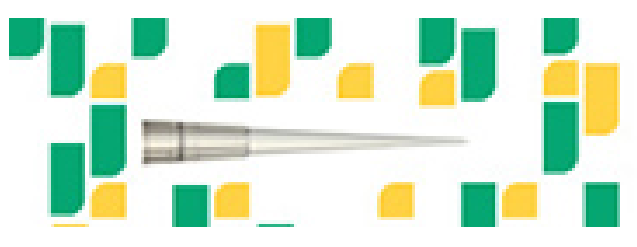

Focused on your science. 